\title{
An Adjustable Differential Protection Scheme for Microgrids with Inverter-Based Distributed Generation
}

\author{
Zaid Alhadrawi ${ }^{1}$, M. N. Abdullah ${ }^{2}$, HazlieMokhlis ${ }^{3}$ \\ ${ }^{1}$ Department of Electrical Engineering, Faculty of Engineering, University of Kufa, IRAQ, \\ zaidt.alhaddrawi@uokufa.edu.iq \\ ${ }^{1,2}$ Green and Sustainable Energy (GSEnergy) Focus Group, Faculty of Electrical and Electronic Engineering, \\ Universiti Tun Hussein Onn Malaysia, 86400 Parit Raja, BatuPahat, Johor, MALAYSIA, \\ mnoor@uthm.edu.my \\ ${ }^{3}$ Department of Electrical Engineering, Faculty of Engineering, University Malaya, 50603 Kuala Lumpur, \\ MALAYSIA, hazli@um.edu.my
}

\begin{abstract}
This paper presents an adjustable differential protection scheme for microgrids with inverter-based distributed generation. In this study, a microgrid protection schemehas proposed based on positive sequence current and mode detection to overcome the limitations of conventional differential protection. The proposed protection scheme used a fault current magnitude andundervoltage protection to distinguish between theislanded mode and the grid-connected mode. The fault currents and voltages retrieved at the two ends are reprocessed to determine the faulty phase. Then, the differential of positive sequence current is used for fault detection and isolation. The main feature of the proposed scheme is its ability to protect a microgrid for loop and radial topology in the islanded mode and the grid-connected mode against all types of faults. Furthermore, the proposed scheme reduces a computational burden and communication units and considers the unbalanced loads for most distribution networks. The effectiveness of the proposed scheme is proved by the PSCAD/EMTDC software simulation of a case study. The simulation results show the ability of the presented scheme.
\end{abstract}

Key words:Microgrid, Differential scheme, Distributed generation, inverter-based DG.

\section{INTRODUCTION}

Microgrid has become a common term for distribution networks that contain distributed generation (DG), particularly inverter-based DGs (IBDGs) that are represented mainly by solar photovoltaic (PV) and doubly-fed induction generators (DFIGs) [1],[2]. The ability of a microgrid to operate in both modes, islanded and grid-connected, making it more reliable and less expensive. In addition, a microgrid helps to reduce power losses in a power network, increase the stability of the network, and enhance the power quality [3]-[5].On the other hand, the power system is affected, particularly the protection system, where the radial distribution network will be dispersed by multi-source systems. Moreover, the fault current magnitude of the islanded mode is different from the grid-connected mode [6],[7]. Therefore, the traditional overcurrent protection of a distribution network can no longer protect the microgrid. Different microgrid protection schemes have been suggested recently in the literature against faulty situations. The authors of [8]-[10] proposed an adaptive scheme for a microgrid with synchronous generators. The authors of [11] proposed a protection centre to adaptively monitor the currents of the feeder continuously. The measurements of each protection zone are collected in the microgrid protection centre via communication links to detect the faults. Therefore, this type of protection is expensive.The work in [12] adaptively changed the protection settings of all overcurrent, which used optimum protection settings. The scheme suffers from the complexity of calculations due to the change of microgrid operation mode, unbalanced loads, and transients during the disconnection or connection of DG units.Other researchers have resorted to apply signal processing methods to sort the fault and normal states. The papers [13]-[15] employed Fourier transform to estimate the fundamental component of the inputs. Meanwhile, the studies [16]-[18] applied the approach based on wavelet transform to protect microgrids from different faults that may occur. The schemes need a correct signal synchronisation with high sampling frequency, which is unserviceable because the DSP (digital signal processing) hardware is uneconomical. In addition, the scheme suffers from high computational burden, leading to slower response.Furthermore, differential protection principles have been employed in the literature. The authors of [19] discussed two main issues associated with microgrid operation control and protection. They used a traditional differential relay at both sides of each line. This scheme is very costly for a large system because it needs to connect all system devices to the control centre. The paper [20] suggested a protection scheme is mainly based on the differential relay.However, they did not consider the grid-connected mode, loop configuration, double line to ground, and line-to-line faults. A current differential protection was used in [21]. The proposed scheme deals with many quantities (i.e., $\mathrm{Ia}$, Ib, Ic, negative and zero currents); therefore, the scheme requires more channels and creates computational burden. 
Also, the authors did not consider the fault current magnitude variation due to microgrid modes, fault types, and unbalance loads that lead to the blinding of protection or false tripping. A differential protection scheme based on the differences in the current frequency components was proposed in [22] to detect and isolate faults for the islanded mode only. Also, [23] used a differential scheme based on symmetrical components with a central communication system for the islanded microgrid. Fuzzy process was used in [24] with the Hilbert space-based power theory to enhance differential protection performance. The scheme was limited to the grid-connected microgrid and neglected the islanded mode. A positive sequence current proposed in [25] instead of the phase current presented into the differential protection. The most important limitations of this scheme are the scheme ignored the islanded mode and disregarded the most common fault type (i.e., single-phase fault). After a careful study of the protection schemes accessible in the literature, it is concluded that differential schemes are a suitable method to protect a microgrid. This is because the schemes can overcome the problems of coordinating a large number of series protections and low fault current supply from inverted-based DGs. However, there are problems associated with this scheme, which are related to the fault current magnitude difference as a result of the change of operation mode, fault types, or unbalance loads that lead to the blinding of protection or false tripping. Furthermore, a conventional differential relay normally employs three differential units to cover all fault types; therefore, it requires more channels and creates computational burden. In addition, the aforementioned schemes have not been examined for other expected disturbances; hence, the schemes could fail to operate correctly during non-fault events. The protection centre used by several previous schemes caused additional cost as multi-channels are required to connect all protection devices. Therefore, it is necessary to find a suitable protection scheme capable of solving these problems.This paper proposed an adjustable differential scheme for microgrid protection based on positive sequence current and detection mode to overcome the limitations of conventional differential protection. The proposed scheme is able to protect looped and radial microgrids under all possible circumstances in both operation modes. The effectiveness of the proposed scheme is provedby PSCAD/EMTDC software simulation of case study. The main contributions of this scheme are as follows:

-Reducing computational burden and communication units.

-Considering both modes of microgrid operation (i.e., grid-connected and isolated).

-Detecting and identifying the faulty line in a microgrid during high penetration of inverter-based DG.

-The ability of dealing with radial and loop configuration, and avoiding the need to modify protection devices with each configuration.

The remaining of the paper is arranged as follows. The background of differential protection is presented in Section 2. Section 3 debates the proposed protection scheme. Section 4 discusses the test system and the simulation results. Finally, in Section 5, the principal conclusions of this study are presented.

\section{DIFFERENTIAL PROTECTION METHOD FOR MICROGRID FEEDERS}

Differential protection method has been widely used as the main protection of an electrical unit such as a generator, bus, transformer, or power line due to its great performance. The method is one of the highest sensitive and powerful methods of presenting protection against faults for the islanded mode and grid-connected mode [1]. The concept of differential protection is uncomplicated, where it is based on the fact that any fault inside an electrical apparatus would result in the current entering the apparatus to be different than the current leaving the apparatus. Thus, the two currents can be compared and a trip output can be issued if the difference exceeds the threshold value. Consider a system shown in Figure 1. The current coming in the first end (I1) must be similar with the current leaving the second end (I2). The two currents do not remain equal when a fault occurs between the two ends. Alternatively, one could form an algebraic sum of the two currents entering the protected apparatus as presented in (1):

$$
I_{r}=I_{1}+I_{2}
$$

Under a normal operation, ideally, the magnitude ofdifferential current should be zero. In practical, it has a small value, both under healthy conditions and external faults due to the current transformer error, ratio mismatch, or line charging current [26].Until recently, the differential protection method has not been applied for line protection due to the distances involved. For a three-phase line, six communication links would be required: one for the neutral, one for each phase, and two for tripping the circuit breakers. However, as computers are becoming more diffused and communication is more developed, line current differential protection has become popular [27]. The application of current differential protection to microgrid lines requires the consideration of problems associated with this scheme, which are related to the fault current magnitude difference to avoid the blinding of protection or false tripping. In this paper, a modified differential current protection that used the differential of positive sequence current for both feeder sides is proposed.

\section{PROPOSED PROTECTION SCHEME}

This paper suggests a comprehensive protection scheme that is able to protect any type of microgrid for all possible configurations against various types of faults. The proposed protection scheme used a fault current magnitude andundervoltage protection to distinguish between the islanded mode and the grid-connected mode. The fault currents and voltages retrieved at the two ends are reprocessed to determine the faulty phase. Then, the differential of positive sequence

current is used for fault detection and isolation. The procedures of the proposed scheme are presented in Figure 2.The proposed scheme consists of two parts. The first part is the mode detector to choose the appropriate settings and the second part is the fault detection as shown in Figure 3. 


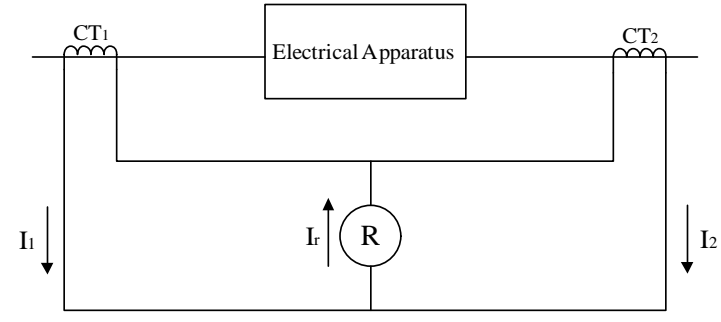

Figure 1: Differential Protection Principle

\subsection{Mode detection}

Although the differential protection scheme can deal with small fault currents efficiently, a misoperation may occur if the scheme is not adjusted accurately due to disconnected DG, transients, or load changes. A microgrid is isolated from the main grid by opening the main circuit breaker at the PCC. A whole communication network is required to inform all protective devices in the microgrid and this approach is expensive. In this paper, the undervoltage and overcurrent principle is relied on to deal with each mode independently without using a communication network, where the voltage and current of each phase are monitored simultaneously. In order reduce calculation complexities and communication channels, a sequence analyser is used to transform abc quantities to positive, negative, and zero sequences. Only positive sequence is employed as the sequence is available in all types of faults as shown in Table 1.

The positive sequence component can be decomposed from three phase systems as shown in (2) and (3):

$V_{a}^{1}=\frac{1}{3}\left(V_{a}+a V_{b}+a^{2} V_{c}\right)(2)$

$I_{a}^{1}=\frac{1}{3}\left(I_{a}+a I_{b}+a^{2} I_{c}\right)(3)$

Where $a=e^{120^{\circ}}$ and $V_{a}^{1}, I_{a}^{1}$ are the positive voltage and positive current sequence, respectively.

The scheme provides monitoring of system voltages and compares it with a specified voltage threshold. For normal operation, the voltages are within permissible limits but during fault, the voltages fall below a specified threshold. This is implemented using a logical circuit comparator thatassigns an output value of " 1 " when the voltage drops and an output value of " 0 " for normal phase voltage.

The magnitude of fault current varies with microgrid circumstances, particularly mode of operation and fault type. Therefore, this study proposed a method that allows the protection scheme to adapt its settings automatically according to the operation modes. The faulted current threshold is stored for each type of fault for both operation modes. The magnitude of fault current (I) is within the two ranges as shown in (4) for the island mode and (5) for the grid-connected mode:

$I i \leq I<I g(4)$

$I \geq I g$
Where $I_{i}$ is the threshold value of positive current in the island mode and $I_{g}$ is the threshold value of positive current in the grid-connected mode.

\subsection{Fault detection}

This stage is based on the differential protection principle as mentioned earlier in Section 2. It can overcome the problems of coordinating a large number of series protections and low fault current supply from inverted-based DGs.However, it has a fixed threshold value that leads to misoperationor protection under-reach as a result of changing

Table 1:Symmetrical Components Associated with Each Type of Fault

\begin{tabular}{|c|c|}
\hline Fault Type & Sequence Component \\
\hline Single line to ground (SLG) & Positive + Negative + Zero \\
\hline Line to line (LL) & Positive + Negative \\
\hline Line to line to ground (LLG) & Positive + Negative + Zero \\
\hline Three phases to ground & Positive \\
\hline
\end{tabular}

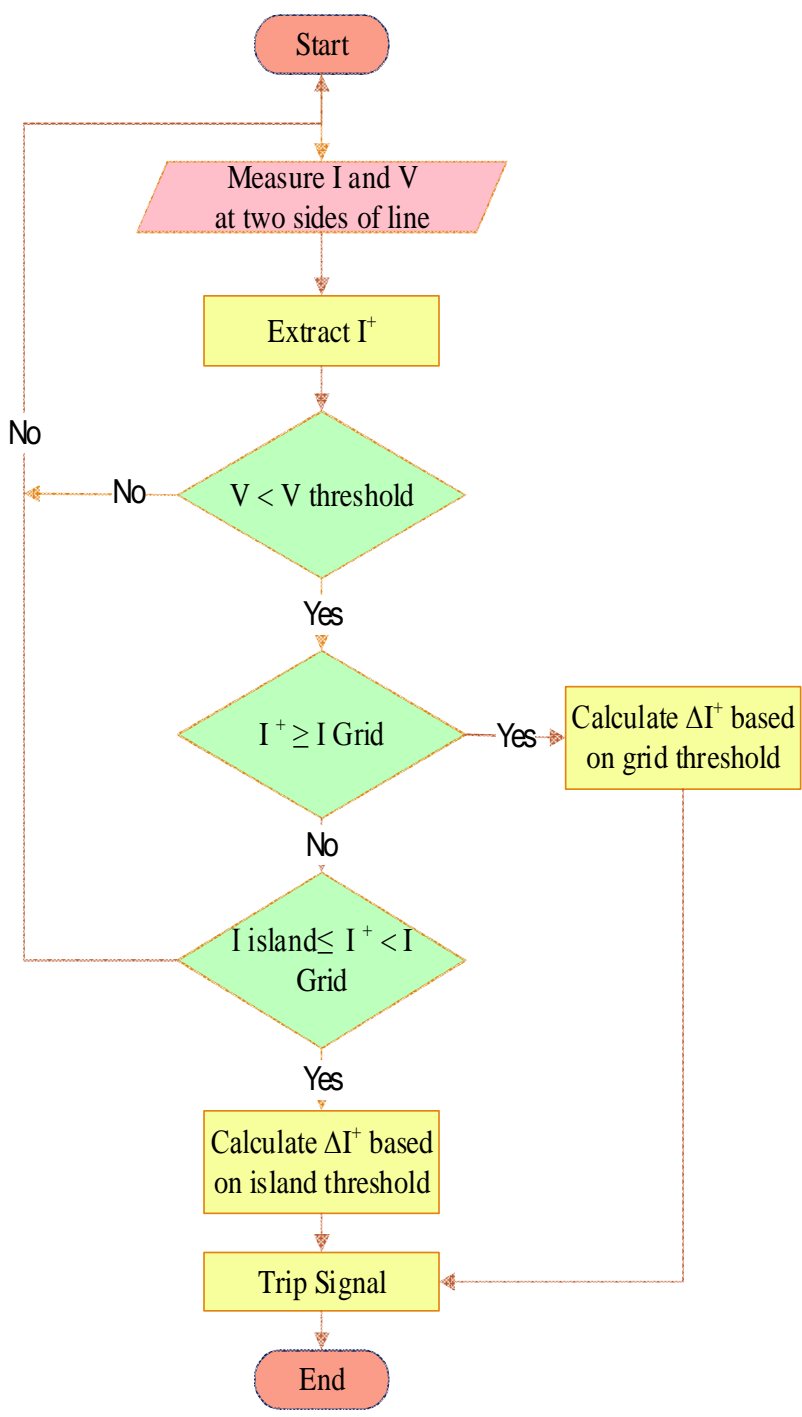

Figure2: Flow Chart of the Proposed Scheme 


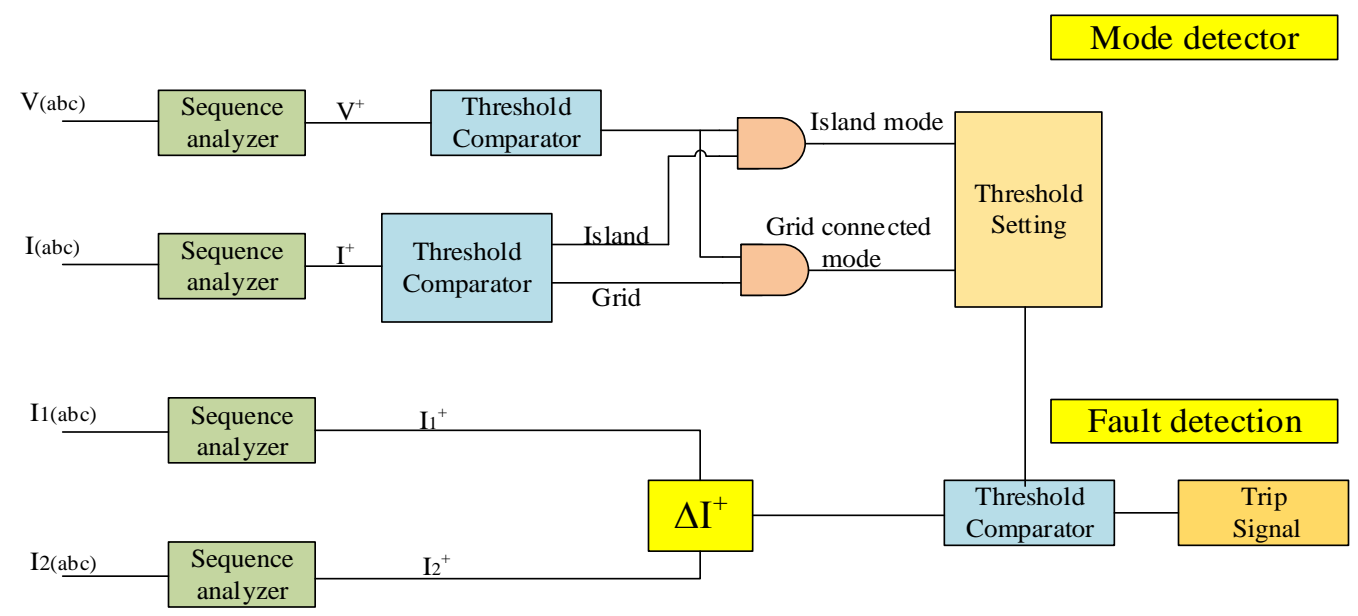

Figure 3: Schematic Diagram of the Proposed Scheme

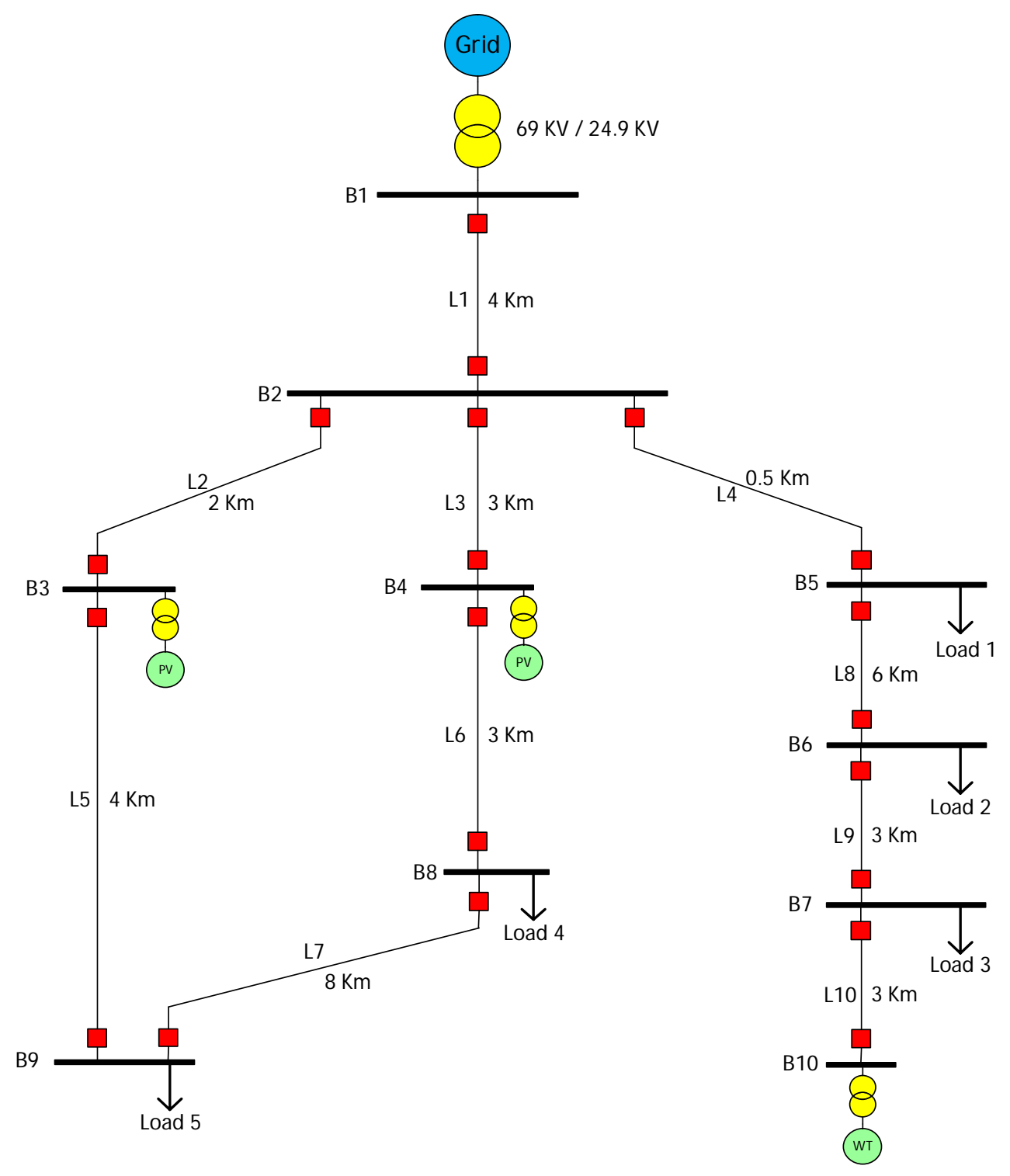

Figure4: Microgrid Case Study 


\section{SIMULATION RESULTS}

To verify the validation of the proposed scheme, the microgrid test system of Figure 4 was performed using PSCAD/EMTDC software. The voltage level of the studied system was $24.9 \mathrm{kV}$ and the operating frequency was maintained at $50 \mathrm{~Hz}$. The microgrid was connected to the grid with a main circuit breaker that can be opened to simulate the effect of the islanded operation mode. As shown in this figure, the microgrid is connected to the main grid by a $69 \mathrm{kV} / 24.9$ $\mathrm{kV}$ Dyn transformer. It also contains two photovoltaic systems (640 KVA) and one wind turbine (504 KVA) that are connected with the power network through a power electronic inverter circuit [28], [29]. Each DG source is interfaced through a 0.4/24.9 $\mathrm{kV}$ transformer. Radial and loop configuration can be achieved when the circuit breakers of L6 are opened or closed. All types of faults (including SLG, LL, LLG, and three phases to ground) were applied to the test the microgrid for different locations in both islanded and grid-connected operation modes. In order to analysis performance of the protection scheme, different scenarios were simulated.

\subsection{RADIAL CONFIGURATION IN GRID-CONNECTED MODE}

The objective of this scenario is to verify the effectiveness of the proposed scheme during the grid-connected mode for radial configuration of the microgrid. In this case, the protection scheme has successfully isolated all types of faults in the microgrid. The protection relays detect all faults for different locations and send the trip signal to relevant circuit breakers. In order to study the performance of all relays, the trip commands were intentionally blocked, and thus the fault remained active. A SLG fault was occurred at line L5 with fault resistance is $10 \Omega$ at simulation time is $0.2 \mathrm{~S}$. In this case, the RMS current value of the faulted phase (a) raised to $0.8 \mathrm{KA}$ while the voltage dropped to 0.55 p.u as shown in Figure 5 (a) and 5 (b) respectively. The current value within grid-connected range, therefore themode detector in the proposed scheme choose the setting of grid-connected mode. The difference between the positive current of the two feeder ends current increase to $0.252 \mathrm{KA}$ so the trip signal was generated. Figure 5 (c) and 5 (d) show the $\Delta \mathrm{I}+$ and trip signal respectively.

\subsection{LOOP CONFIGURATION IN GRID-CONNECTED MODE}

The loop structure provides additional reliability. For the faults on any feeder line, the loads supplied power fromanother side and will remain in service. The loop configuration is achieved by closing the circuit breakers of line L7. The objective of this scenario is to verify the effectiveness of the proposed scheme during the grid-connected mode for loop configuration of the microgrid. Also,the proposed scheme identified all faults typefor differentlocation. Figure6. shows LL fault at L6.

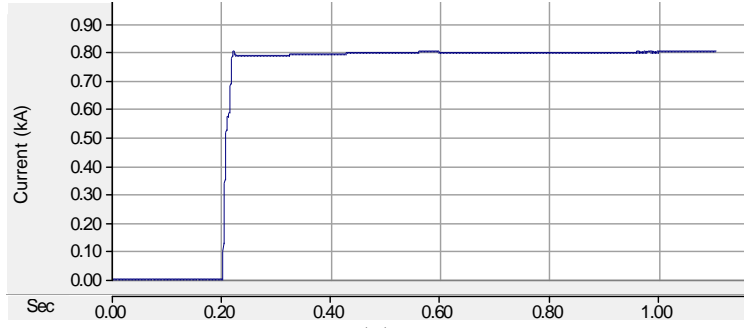

(a)

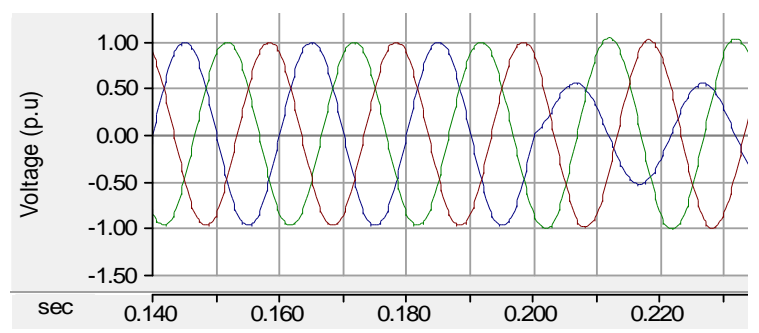

(b)

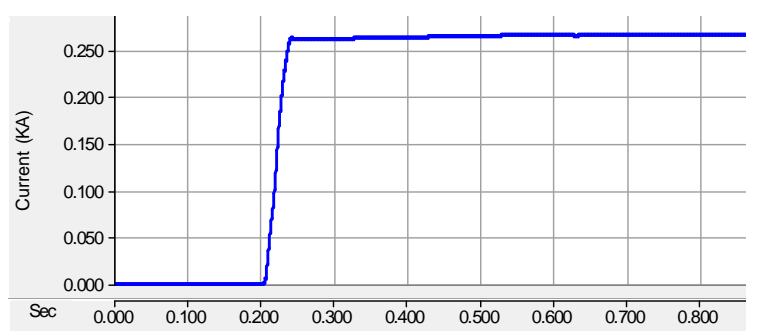

(c)

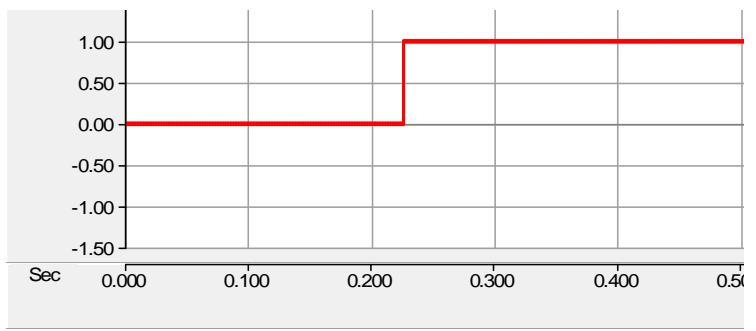

(d)

Figure5:SLG Fault at L5 in Grid-Connected Mode/ Radial Configuration (a) Magnitude Fault Currents (b) Three-Phase Voltages (c) Positive Current Differential (d) Trip Signal

\subsection{RADIAL CONFIGURATION IN ISLAND MODE}

In this case, the fault current level decreased significantly due to the disconnection from the main grid, and the source of generation present is only IBDGs.The objective of this scenario is to verify the effectiveness of the proposed scheme during the islanded mode for radial configuration of the microgrid. In this case, the protection scheme has successfully isolated all types of faults in the microgrid.In this scenario, the difference from grid-connected where the current magnitude is small. 


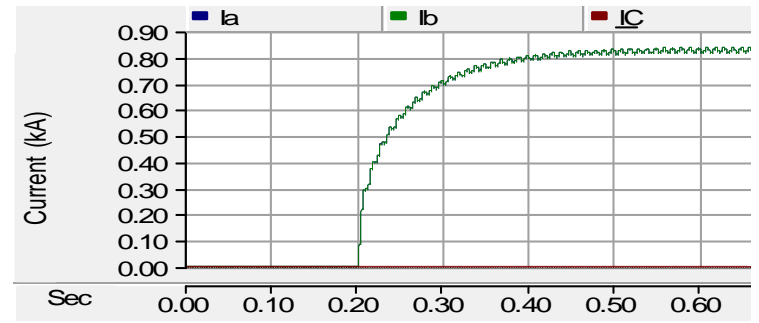

(a)

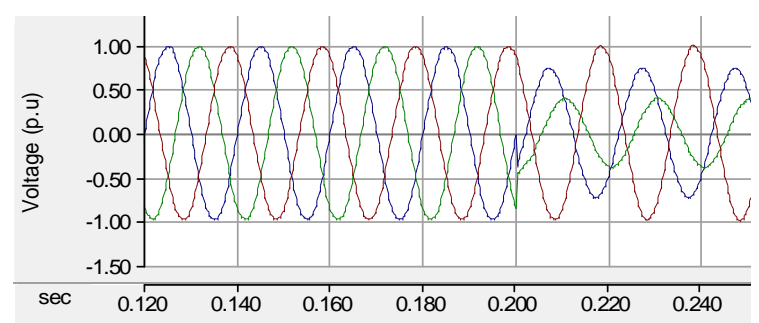

(b)

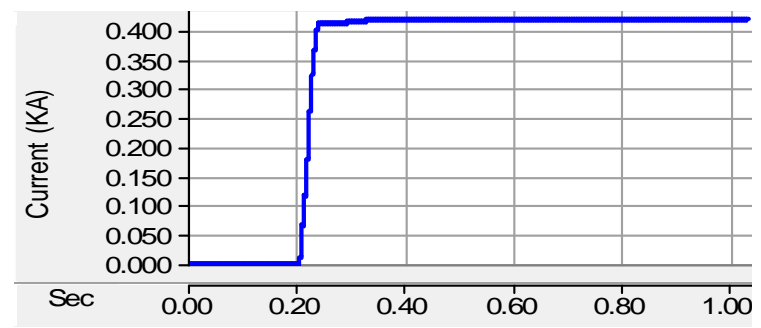

(c)

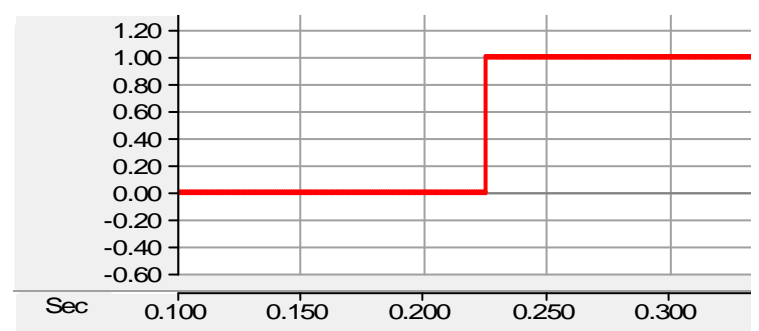

(d)

Figure 6:LL Fault at L6 in Grid-Connected Mode/ Loop Configuration (a) Magnitude Fault Currents (b) Three-Phase Voltages (c) Positive Current Differential (d) Trip Signal

A SLG fault was occurred at line L5 with fault resistance is 10 $\Omega$ at simulation time is $0.2 \mathrm{~S}$. In this case, the RMS current value of the faulted phase (a) raised to $0.015 \mathrm{KA}$ while the voltage decreased significantly as shown in Figure7 (a) and 7 (b) respectively. The current value within island range, therefore the mode detector in the proposed scheme choose the setting of island mode. The difference between the positive current of the two feeder ends current increase to $4 \mathrm{~A}$ so the trip signal was generated. Figure7 (c) and 7 (d) show the $\Delta \mathrm{I}+$ and trip signal respectively.

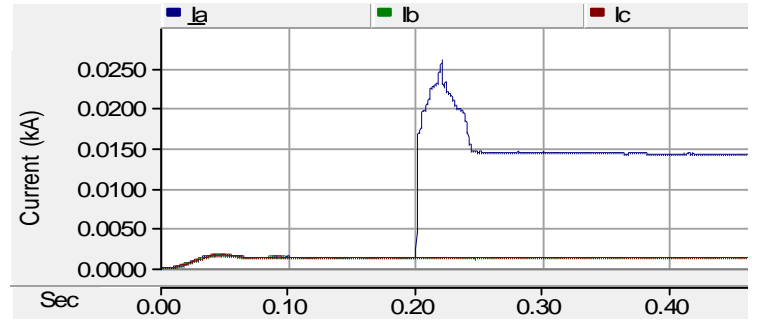

(a)

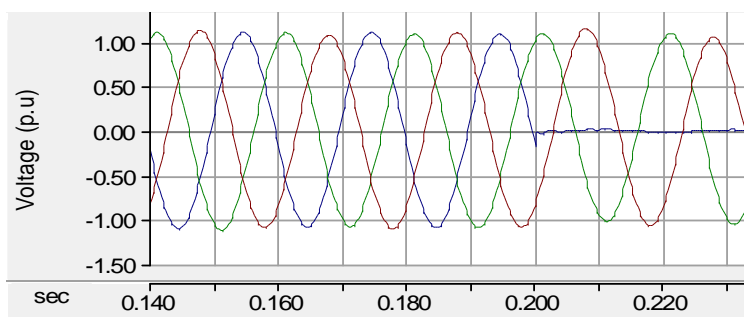

(b)

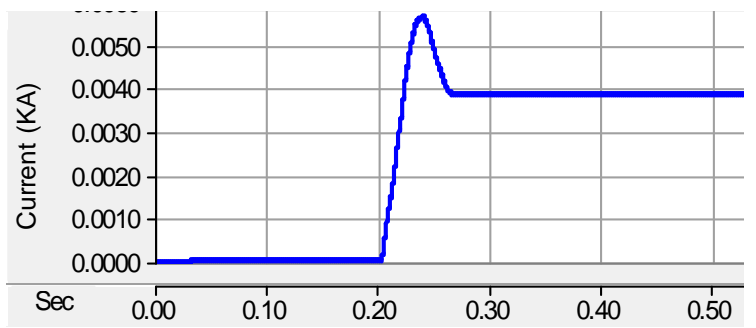

(c)

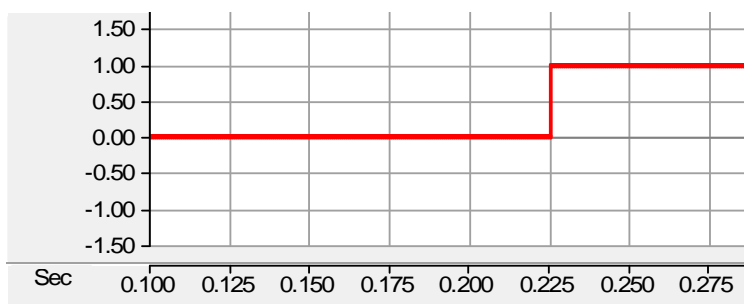

(d)

Figure7: SLG Fault at L5 in Islanded Mode/ Radial Configuration (a) Magnitude Fault Currents (b) Three-Phase Voltages (c) Positive Current Differential (d) Trip Signal

\subsection{LOOP CONFIGURATION IN ISLAND MODE}

The objective of this scenario is to verify the effectiveness of the proposed scheme during the grid-connected mode for loop configuration of the microgrid. This case is largely similar to the loop structure when the grid is connected. However, the transients are smaller due to the lower short circuit capacity of the system. Figure8. show fault current magnitudes, the voltages, the differential of positive current, and tripping signal waveforms, respectively for a LLG fault at L9. 


\subsection{UnBALANCED LOAD}

Usually the loads are unbalanced in the distributionnetworks, so this issue should be taken into consideration when proposing a protection system. The proposed scheme

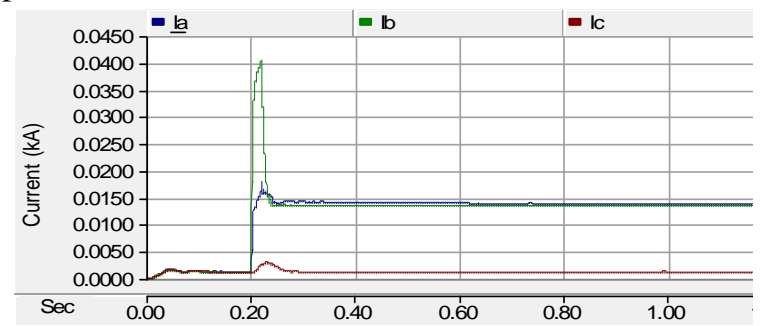

(a)

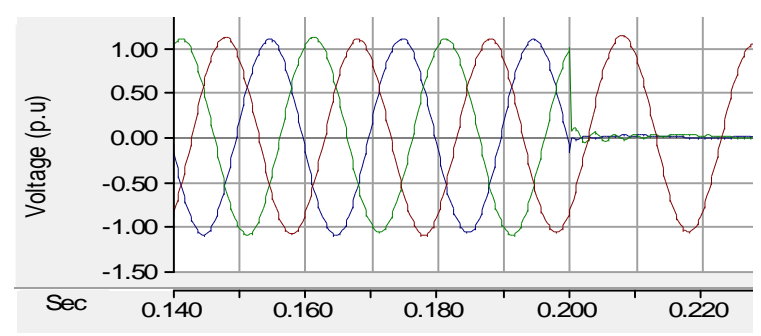

(b)

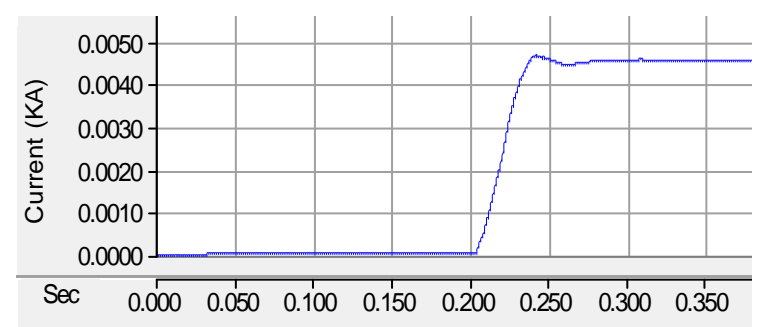

(c)

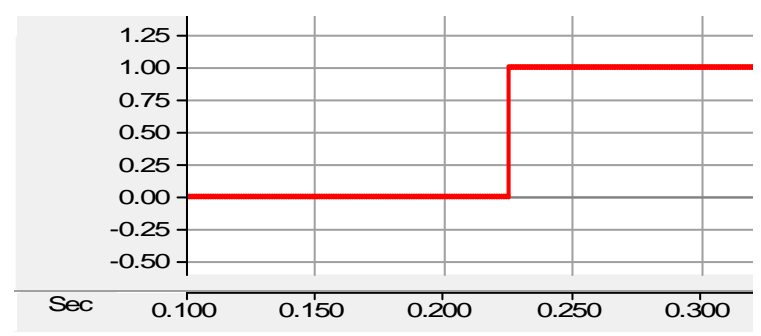

(d)

Figure8:LLG Fault at L9in Islanded Mode/ Loop Configuration (a) Magnitude Fault Currents (b) Three-Phase Voltages (c) Positive Current Differential (d) Trip Signal

based on the positive current component to fit with this issue. This scenario examined the proposed scheme validity for unbalanced load during grid-connected and island modes for radial and loop configuration. For example, a three-phase fault occur at line L6 in grid- connected mode for radial configuration. Figure 9 shows the ability of proposed scheme to detect the fault and isolate it. Also, Figure10 shows a SLG fault was occurred at line L5.

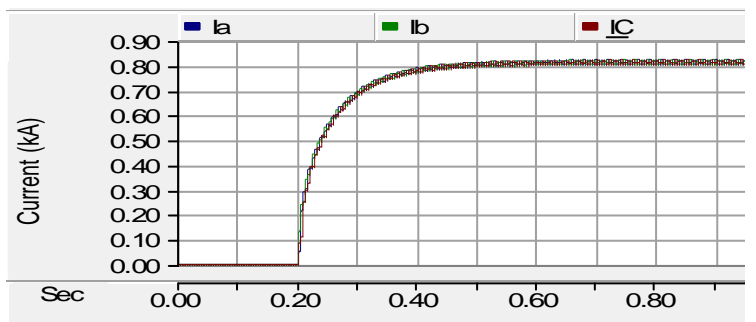

(a)

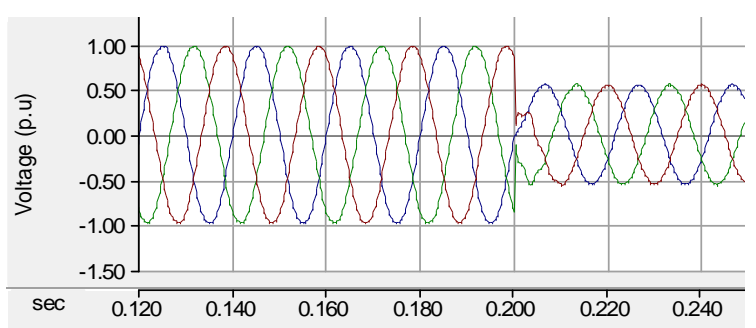

(b)

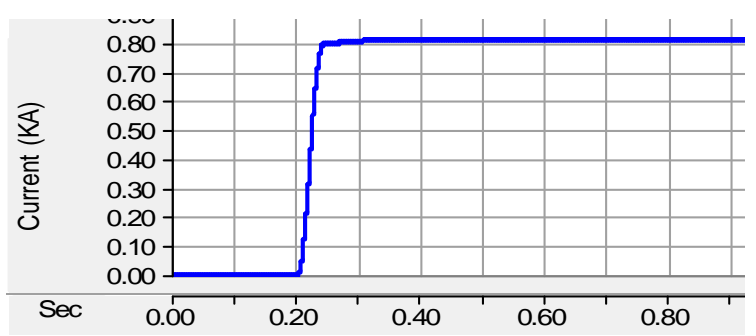

(c)

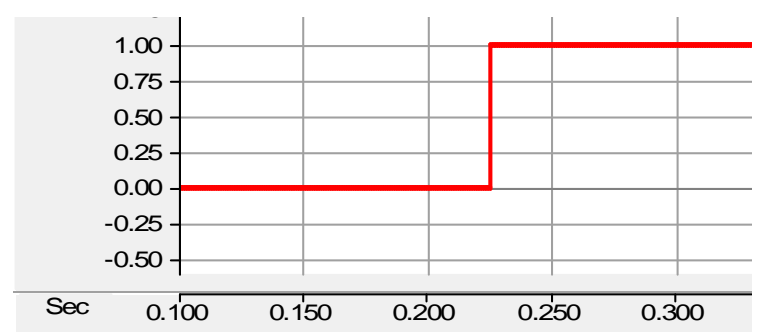

(d)

Figure9: Three-Phase Fault at L6 in Grid-Connected Mode/ Radial Configuration for Unbalanced Load (a) Magnitude Fault Currents (b) Three-Phase Voltages (c) Positive Current Differential (d) Trip Signal

\section{CONCLUSION}

Microgrid protection is a challenge typically due to the growing penetration of DGs, particularly inverter-based DGs. Therefore, traditional protection schemes are not appropriate for a microgrid system. This requires finding alternativeprotection to isolate the faulty zone of network in a minimum possible time. This paper proposed a comprehensive scheme for an inverter-based microgrid. In this scheme, the fault current level and undervoltage protection are used to distinguish between the islanded mode 
and the grid-connected mode. In addition, the differential of positive sequence current is used to detect and isolate the faulted zone. The proposed

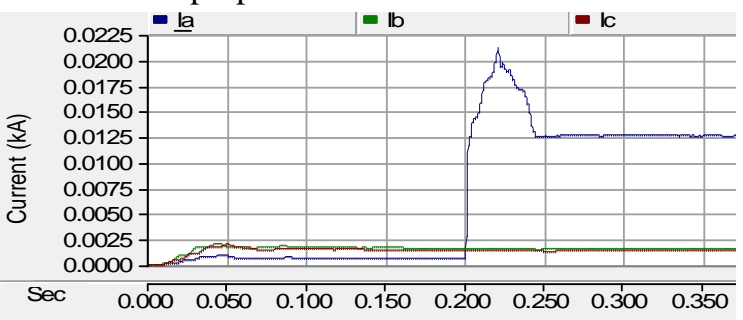

(a)

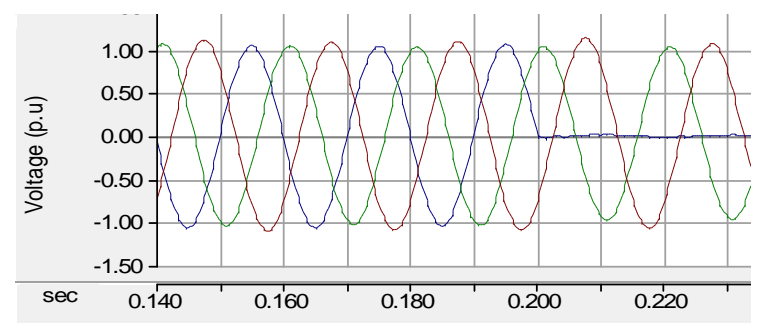

(b)

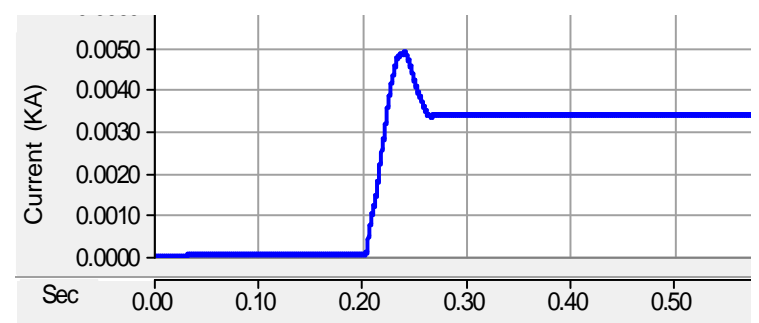

(c)

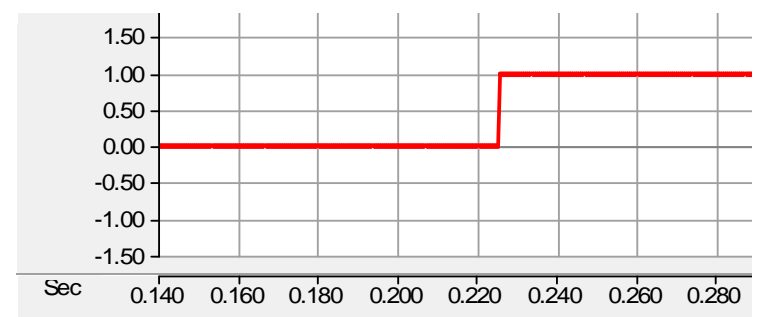

(d)

Figure10: SLG Fault at L5 in Islanded Mode/ Loop Configuration for Unbalanced Load (a) Magnitude Fault Currents (b) Three-Phase

Voltages (c) Positive Current Differential (d) Trip Signal

method does not depend on a central protection. To confirm the effectiveness of the suggested scheme, many cases were simulated in both islanded and grid-connected operation modes for loop and radial configurations. Using PSCAD/EMTDC simulation software, the scheme has been confirmed to be accurate, selective, safe, and has reliable operation of protective devices in all zones for all cases.

\section{REFERENCES}

1. B. Han, H. Li, G. Wang, D. Zeng and Y. Liang. A virtual multi-terminal current differential protection scheme for distribution networks with inverter-interfaced distributedgenerators,IEEE Trans. Smart Grid,Vol. 5 pp. 5418-5431, Septemper 2018.

2. A. A. Kamoona, A. N. alfadli, and I. A. Alshabeeb.New method for oc relay coordination,J. Electr. Comput. Eng., Vol. 2020, pp. 1-11, May 2020.

3. D. A. Gadanayak and R. K. Mallick.Microgrid differential protection scheme using downsampling empirical mode decomposition and Teager energy operator, Electr. Power Syst. Res., Vol. 173, pp. 173-182, August 2019.

4. E. Sortomme, S. S. Venkata and J. Mitra.Microgrid protection using communication-assisted digital relays, IEEE Transactions on Power Delivery, Vol. 4, pp. 2789-2796, Octoper 2010,

5.M.S. Ibbini and A.H. Adawi.Analysis and design of a maximum power point tracker for a stand-alone photo voltaic system using simscape,Int. J. Adv. Trends Comput. Sci. Eng., Vol. 8, no.1, pp. 54 - 56, 2019

6. A.Vandana, R.Mohan, A. Abdul, B. Sujatha and B. N. Kishore.Fault detection in three phase transmission line using wavelet transform algorithm,Int. J. Adv. Trends Comput. Sci. Eng., vol. 8, no.1, pp. 82 - 84, 2019

7. P. Mahat, Z. Chen, B. Bak-Jensen and C. L. Bak.A simple adaptive overcurrent protection of distribution systems with distributed generation, IEEE Trans. Smart Grid, vol. 2, no.3, pp. 428-437, septemper 2011.

https://doi.org/10.1109/TSG.2011.2149550

8. L. Felimar, B. Torrizo, A. Don and M. Africa.Utilizing MINLP-based Hourly dispatch optimization on a droop-controlled islanded microgrid,Int. J. Adv. Trends Comput. Sci. Eng., vol. 8, no.5, pp. 2464 - 2469, 2019

https://doi.org/10.30534/ijatcse/2019/91852019

9. E. C. Piesciorovsky and N. N. Schulz.Comparison of programmable logic and setting group methods for adaptive overcurrent protection in microgrids,Electr. Power Syst. Res., vol. 151, pp. 273-282. October 2017.

10. E. C. Piesciorovsky and N. N. Schulz.Fuse relay adaptive overcurrent protection scheme for microgrid with distributed generators, IET Gener. Transm. Distrib., vol 11, no. 2, pp. 540-549, 2017.

11. O. V. Swathika and S. Hemamalini.Prims-aided Dijkstra algorithm for adaptive protection in microgrids, IEEE Journal of Emerging and Selected Topics in Power Electronics, vol. 4, no. 4, pp. 1279-1286, 2016.

12. F. Coffele, C. Booth and A. Dyśko.An adaptive overcurrent protection scheme for distribution networks, IEEE Trans. Power Deliv., vol. 30, no. 2, pp. 561-568, 2015. 13. D. S. Kumar, D. Srinivasan and T. Reindl.A fast and scalable protection scheme for distribution networks with distributed generation, IEEE Trans. Power Deliv., vol. 31, no. 1, pp. 67-75, 2016,.

14. S. Kar, S. R. Samantaray and M. D. Zadeh.Data-mining model based intelligent differential microgrid protection scheme, IEEE Systems Journal, vol. 11, no.2, pp. 1161-1169, 2017. 
15. S. B. Bukhari, R. Haider, M. S. Zaman, Y. Oh, G.Cho and C. Kim.An interval type-2 fuzzy logic based strategy for microgrid protection, Int. J. Electr. Power Energy Syst., , vol. 98, pp. 209-218, June 2018.

16. X. Li, A. Dysko and G. M. Burt.Traveling wave-based protection scheme for inverter-dominated microgrid using mathematical morphology, IEEE Trans. Smart Grid, ,vol. 5, no.5, pp. 2211-2218, 2014.

17. S. A. Saleh, R. Ahshan, M. S. Abu-Khaizaran, B. Alsayid and $M$. A. Rahman.Implementing and testing d-q WPT-based digital protection for microgrid systems, IEEE Transactions on Industry Applications, vol. 50, no.3, pp. 2173-2185, 2014.

18. J. J. Yu, Y. Hou, A. Y. Lam, and V.O. Li.Intelligent fault detection scheme for microgrids with wavelet-based deep neural networks, IEEE Trans. Smart Grid,vol. 10, no. 2, pp. 1694-1703, 2017.

19. H. H. Zeineldin, S. Member and M. M. Salama, Distributed generation micro- grid operation: control and protection, Power Systems Conference,Clemson, SC, USA,March 2006, pp. 105-111.

20. S. Conti, L. Raffa and U. Vagliasindi. Innovative solutions for protection schemes in autonomous MV micro-grids,Int. Conf. Clean Electr. Power, Capri, Italy, June 2009, pp. 647-654.

21. M. Dewadasa. 'Protection of microgrids using differential relays,' Univ. Power Eng. Conf., Brisbane, QLD, Australia, Sept. 2011 pp. 1-6.

22. A. Soleimanisardoo, H. K. Karegar, and H. H. Zeineldin, Differentialfrequency protection scheme based on off-nominal frequency injections for inverter-based islanded microgrids, IEEE Transactions on Smart Grid, vol. 10, no. 2, pp. 1-8, 2019.

23. E. Casagrande, W. L. Woon, H. H. Zeineldin and D. Svetinovic,A differential sequence component protection scheme for microgrids with inverter-based distributed generators, IEEE Trans. Smart Grid, vol. 5, no.1, pp. 29-37, 2014.

24. A. H. Abdulwahid and S. Wang, A new differential protection scheme for microgrid using Hilbert space based power setting and fuzzy decision processes, IEEE 11th Conf. Ind. Electron., Hefei, China, June 2016, pp. 6-11. 25. H. Gao, J. Li, and B. Xu, Principle and implementation of current differential protection in distribution networks with high penetration of DGs, IEEE Trans. Power Deliv., vol. 32, no.1, pp. 565-574, 2017.

26. A. T. Johns and S. K. Salman, Digital protection for power systems, IET, 1st edn. 1995, pp. 190-199

27. S. H. Horowitz and A. G. Phadke, Power system relaying, John Wiley \& Sons Ltd, 4th edn. 2014, pp. 158-160.

28. S. Mirsaeidi, D. M. Said, M. W. Mustafa,M.H. Habibuddin and K.Ghaffari,A protection strategy for micro-grids based on positive-sequence impedance,Distributed Generation and Alternative Energy Journal, vol. 31, no.3, pp. 7-32, 2016.

25. S. Mirsaeidi and M. W. Mustafa, A protection strategy for micro-grids based on positive-sequence component, IET Renewable Power Generation, vol. 9, no. 6, pp. 600-609, 2015.

https://doi.org/10.1049/iet-rpg.2014.0255 